\title{
The Perks and Downsides of Being a Digital Prosumer: Optimistic and Pessimistic Approaches to Digital Prosumption
}

\author{
Davide Dusi
}

\begin{abstract}
The recent evolution of users' position and agency in digital environments absorbs the attention of several scholars in different fields of study. Users' new ontological status as prosumers, simultaneously producers and consumers, and their role regarding productive paradigms has raised a lot of contrasting opinions. Different discursive techniques are employed to investigate production practices in digital worlds and are often crafted with the conventions of utopian and anti-utopian approaches. Nevertheless, the adoption of optimistic or pessimistic analytical and rhetorical strategies appears to be prejudiced towards the study of emerging online practices. In reality, the analysis of positive and negative approaches to productive paradigms in digital environments results in the detection of their limitations in reaching a comprehensive understanding of the investigated phenomena. Therefore, the adoption of a more neutral perspective is suggested, one that could potentially foster a holistic approach and therefore a broader and deeper comprehension of the analyzed phenomena.
\end{abstract}

Index Terms-Digital prosumption, ICT, productive paradigms, optimistic and pessimistic approaches.

\section{INTRODUCTION}

The recent advancements of Information and Communication Technologies (ICT) led to a progressive change of the user-technology relationship [1], [2]. In the current scenario, the renewed agency of users and their influence on online production practices absorb the attention of scholars in several disciplines. The most renowned theorization regarding the current ontological status of individuals in digital worlds is the one that addresses them as prosumers, namely producers and consumers at the same time [3]. According to this concept, digital users are involved in prosumption activities; activities which entail simultaneous production and consumption [3].

Notwithstanding the increasing importance of prosumers in digital worlds, there does not seem to be an agreement about the role played by or assigned to them. Different analytical and rhetorical strategies are employed to investigate prosumers' online practices. Optimistic and pessimistic positions advance hand in hand with the technological progress, and are often crafted with the conventions of utopian and anti-utopian approaches [4]-[6].

Manuscript received November 28, 2014; revised January 21, 2015. This work was supported by BOF: Bijzonder Onderzoeksfonds, the Special Research Fund of Ghent University

D. Dusi is with the Centre for Social Theory of Ghent University, Belgium (e-mail: davide.dusi@ugent.be).
Positive approaches consider prosumers as the main subjects in the emerging online production practices, whereas negative ones regard them as victims of the perpetuation of traditional capitalist logics. They question the mistreatment of users' data and labor and underline the potential exploitation of technology for control and repression. Overall, the anti-utopian approach emphasizes the dark side of the promises for technological and social progress and acts as a counterbalance to the utopian one [6], [7].

This paper investigates the current debate on users' role with regard to productive paradigms in digital environments. The aim is twofold: on one hand to provide an overview of current opposing theorizations and perspectives regarding digital prosumption, and on the other hand to show the limitations of positive and negative approaches for the study of online production practices. Consequently, this manuscript is divided in three parts. The first part describes the changes of users' role and agency in digital worlds and the rise of the so-called digital prosumer. After a clarification of the theorization of prosumptiom and the explanation of its recently re-worked version, the second part will serve to analyze contrasting approaches to digital prosumption and to clarify the likely fate of the users as envisaged by different perspectives. The third part will help to analyze further the role played by or assigned to prosumers according to opposing perspectives and to show the limitations of contrasting approaches to reach a broad and deep understanding of online production practices and emerging socio-technical arrangements. Finally, the adoption of a more neutral and holistic approach for the study of digital prosumption and productive paradigms in digital environments is suggested.

\section{Productive Paradigms in Digital EnVironments: THE RISE OF THE Digital PROSUMER}

In the last decades the advancements and pervasiveness of Information and Communication Technologies contributed to the redefinition of the user-technology relationship as well as of users' role in digital environments [1]. The increased agency of users fostered progressive changes with regard to productive paradigms in digital worlds [8], [9]. These changes resulted in the emergence of new modes of production that called into question our traditional distinction between production and consumption.

The diffusion of the Internet on a global scale as well as the evolution of the Web 2.0 [10] encouraged the increase of user-generated content and the emergence of online practices 
to share them [2]. Recently, the development of these practices has expanded considerably [2]. This development changed the ways in which individuals obtain and exchange information and fostered the emergence of alternative processes through which the information itself is generated [11]. Nevertheless, the production of an increasing amount of user-generated content is not the only phenomenon that we are witnessing in digital environments.

In reality, digital worlds are characterized by heterogeneous users engaged in diversified usages of the Internet. Besides the users who generate, revise and share online content, there are those who exploit their high digital skills to transform ICT features [12] in the attempt to make the digital tools at their disposal suitable for their purposes [13]. These purposes can be related to the satisfaction of personal needs or to the desire to act socially and politically. In addition to this kind of users, there are individuals who commit themselves to the production of new digital tools, which they themselves need. One representative example of the abovementioned production practices is the category of Do-it-Yourself online communities [14] and the related websites created to host thousands of user-developed projects. Other examples can be found in phenomena like the online Hacktivism [15] and the Open Source Software movement (e.g. Linux, OpenOffice).

The above socio-technical arrangements foster the transformation of labor practices into less hierarchical, more team-driven enterprises [8]-[16]. They promote decentralized production processes in which activities are distributed among several proactive actors. Moreover, these processes do not always follow a predictable path [17]. The emerged and emerging production practices in digital worlds are redefining several social fields or systems (e.g. economy, education, art) that used to be structured by means of a dual, hierarchical division of labor (e.g. teacher-pupil, writer-reader, sender-audience, designer-end user). This redefinition is the result of the exploitation of ICT advancements as well as of the possibilities provided by the Web 2.0 [10] to work online individually or to collaborate in small or big groups [17]. The greater access to tools which allow the organization of activities [9] and the generation and sharing of content [11] have fostered the change of the ontological status of individuals from passive users to potentially active participants [9].

Several concepts and theorizations were and are employed to reach a deep understanding of the renewed users' agency and of their ontological status regarding productive paradigms. The most renowned concept is the one of prosumer, and the related theorization of prosumption [18][20]. The prosumer, according to the original theorization of Alvin Toffler [18], is an individual who is both producer and consumer of goods at the same time. As recently proved, the concept of the user as prosumer is not new, nor is its application to productive paradigms, especially regarding material worlds[20], [21]. However, it is a figure that finds a broadened and renewed agency and popularity in digital environments. Indeed, digital worlds seem a particularly fruitful environment with regard to the emergence and development of practices in which users are engaged in the production of content, features and tools that they will consume and, more generally, in activities which entail simultaneous acts of producing and consuming. After a brief explanation of this concept, one could ask: what online practices can be considered as prosumption activities, namely activities that entail production and consumption at the same time? And, what kind of online users can be defined as digital prosumers?

The latest version of the abovementioned theorization, developed by George Ritzer [3], considers prosumption as an interrelated process of production and consumption that characterizes every human activity. Ritzer's reworked version of the concept of prosumption originally elaborated by Toffler [18] derives from his previous work regarding the so-called "McDonaldization of society" [22]. This work calls into question all those activities that put customers, users, to work. Its result is the awareness that in the current society people, while under the assumption that they are merely consuming, are in fact involved in a variety of production-related activities and services (e.g. garbage disposal at fast food restaurants, IKEA's furniture assembly etc.). The idea of prosumption embraced by Ritzer differs from the one originally developed by Toffler. According to Toffler [18], individuals are prosumers only regarding certain activities and the society is characterized by three different sectors (production, consumption, prosumption) within which individuals move. Differently from Toffler, Ritzer [3] argues that individuals are always prosumers, namely they always are in the prosumption sector. This is because, Ritzer claims, production always involves consumption and there is always production involved in consumption [3]. This re-worked version of Toffler's theorization of prosumption represents the denial of the existence of a production and a consumption sector of society and the acknowledgment of only one sector in society, namely prosumption.

The prosumption approach enlarges the range of online practices regarded as relevant for productive paradigms and expands the user base usually taken into account by analysts as taking part in online production. Generally, there is the tendency to think about productive paradigms and users' increased agency referring to those users who are engaged in the generation and revision of content or in software development [11]. Other times the reference is to those who collaborate with ICT firms and companies on the development of new services and digital products [23], [24] or to those who avoid contact with firms and collaborate with other users, engaging in practices of online peer-production [9], [17] Instead, with the last development of the theorization regarding the prosumer, the main focus on the "active users" ceases to exist. Every user is a prosumer, namely is simultaneously involved in production and consumption activities. Accordingly, every online practice can be considered a prosumption related activity.

Consequently, all the users are taken into account and regarded relevant for production practices in digital worlds; independently from what they do. For example, even an apparently passive user who only "consumes" online content and services without producing or collaborating in the production of any of them, is participating in a production process. This kind of user can contribute to, for instance, the 
production of data used by third parties for business interests (e.g. commercials, market researches) or to the overexposure of data that will be used by online systems of control and surveillance.

The revised concept of prosumer, especially if applied to digital environments, enables us to consider every kind of usage of the Internet, every production process that is taking place online, and every digital user as relevant for productive paradigms in digital environments. This notwithstanding users' diversified degree of influence on or participation in production practices in digital worlds. However, the awareness that every individual who is taking part in online practices can be considered a prosumer whose activities are integrated, more or less consensually, in emerging practices of online production, raises critical questions and gives life to contrasting opinions. While some scholars celebrate the empowered role of users, their agency and the potentialities of their renewed ontological status, others worry about a potential exploitation of users' work and data, and overall of their current position in digital environments. As a consequence, a strong debate is rising on the pros and cons related to the condition of users as prosumers. Several approaches try to understand what the likely fate of digital prosumers will be while investigating the potentialities related to their usage of Information and Communication Technologies and the ways in which ICT companies and agencies use, exploit or treat this usage [25].

\section{PROS AND CONS OF DigITAL PROSUMPTION}

Given its ability to enable users to engage in a wide variety of possible activities, Internet is accompanied by great expectations [26]. These great expectations lead somehow to considering current Information and Communication Technologies, and the emerging online practices, as being able to escape the difficulties, disillusions and failures that were encountered with previous generations of ICT [26]. Particularly, the new ontological status of users as prosumers and the effects of digital prosumption on the economic, social and political systems seem to absorb the attention of scholars in different fields.

\section{A. The Perks of Being a Digital Prosumer}

The increasing importance of users and the emergence of new productive paradigms in digital environments have been considered by several scholars as the core activity of a new innovative and creative economic system [8]. This is because the advancements of ICT offer opportunities for individuals to engage in practices which permit them to be creative, connected and proactive [16] as well as to promote alternative ways of production [8], [9]. Nevertheless, besides the economic ramifications of users' online participation and collaboration, even the social and political effects of these practices must be considered. In reality, individuals are enabled not only to generate and share information or to create and transform digital tools, but also to become more active and committed citizens, to expand their social life and to engage further in political activities and initiatives. This leads to the interpretation of ICT as tools of empowerment for people and, according to the ICT enthusiasts, encourages us to give ourselves over to these increasingly powerful technologies able to conduct individuals towards a bright future. Therefore, a positive narration of prosumers' role and agency in digital environments has been developed to underline the potentialities of emerging socio-technical arrangements in promoting social progress through technological development and power reconfiguration through participation [6].

Positive analytical and rhetorical strategies are employed to promote the advantages of being a digital prosumer. For some scholars the emerging socio-technical arrangements and online production practices represent "a closing of the economic and ontological gap between consumption and production" [27]. Moreover, the engagement of individuals in practices of transformation and improvement of already existing products could constitute, even in digital worlds, a form of resistance to the alienating effects of society [28]. According to the analysts of the prosumption phenomena, both mainstream and progressive, the prosumption society will probably be a non-alienated society [29]. This is because, theoretically speaking, the user as a prosumer is re-connected to his/her creative essence as well as with other people [29]. For this reason prosumption can be considered as intensively social and able to foster a mismatch between a private property-based economy and collective labor power [30].

In the last decades, the ever increasing access of people to ICT and their consequent participation in product development also led to the concept of "democratization of innovation" [23]. This idea considers user-centered innovation as a very powerful phenomenon and led increasingly to user-engagement during design processes. Consequently, always more users, digital prosumers, are involved by ICT companies and agencies in the development of new products. Furthermore, new technological artefacts and features created or developed by prosumers are embedded in already existing web-based tools and seem to make space for new ICT development scenarios [7], [31], [32].

As argued, digital prosumption is considered the core activity of a new economic system in different fields [8]. However, the emerging productive paradigms are regarded as beneficial not only for the economy but also for the entire society. Some authors investigate emerging socio-technical arrangements in an attempt to demonstrate how empowered users can impact and influence democracy and, more generally, affect politics [33]-[35]. Their analyses argue about the importance of users' online participation and collaboration and of their engagement in the generation and circulation of information for democracy and processes of open government. Accordingly, the empowerment of users through ICT and their engagement in online practices would foster not only an economic reorganization but also a socio-political one [33]-[35].

As already stated, the effects of users' online practices would also entail both economic and social improvements. For instance, users involved in online peer-production practices work most of the time without market and managerial hierarchies. They are engaged in activities as volunteers, namely they offer their free labor and spare time to achieve common goals that can be relevant for the group to 
which they belong and/or for the entire society. According to some analysts of these phenomena, they give life to a socio-economic system of production and engage in practices that allow them to "exhibit and experience virtuous behaviour" [9, 394]. This would result in a society more conducive to virtuous individuals and, therefore, in individuals who adopt virtues as "attributes of what they see as their self-definition" [9, 394]. Consequently, the emerging socio-technical arrangements that promote online collaborative production offer not only a remarkable medium of production of information and cultural and digital goods, but could also serve as a "context for positive character formation" $[9,395]$.

\section{B. The Downsides of Being a Digital Prosumer}

Notwithstanding the increasing importance of prosumers in digital worlds and of their participation in ICT usage and development as well as in social and political activities and initiatives, some questions have been raised. Some authors consider the emerging socio-technical arrangements as perpetuations of the traditional capitalist logic and they urge us to consider the themes of control, surveillance, intellectual property, etc. [36], [37]. In addition, they question the exploitation of digital prosumers' free labor by ICT companies and agencies [38], [39]. They regard the relationship between prosumers' free labor and ICT companies as an "extraction of unpaid, coerced, and alienated labor" [40, 278]. Indeed, the exploitation of users' free labor seems to be the main theme adopted by critical approaches when it comes to giving an account of the activities of digital prosumers. These activities are described as "pleasurably embraced and at the same time often shamelessly exploited" [37], [38].

The approach of certain ICT firms and companies to the labor of digital prosumers and to online production practices led some authors to talk about prosumer-management [26]. The term prosumer-management refers to the strategies adopted by vendors in the attempt to sort and categorize their user base, and to make users' activities and collaboration fit with their business models [26]. In other words, it can be considered the way in which ICT firms and companies try to maximize users' insights and needs to develop products [27]. With regards to this topic, even George Ritzer, the most renowned analyst of prosumption, seems to be pessimistic towards the condition and fate of prosumers. Indeed, he criticizes Toffler's theorization of individuals as prosumers, arguing that it fails to anticipate the cooptation that takes place in prosumption, namely it fails to anticipate the way in which owners and business people co-opt the prosumers [3].

In addition to the abovementioned critical aspects of digital prosumption, scholars call into question the commodification of privacy on the Internet, namely the economic-practical commodification of personal data and its problems [41], [42], and the power structures that facilitate control and regulation [43]. They claim that dominant online business models conflict structurally with users' need for privacy and call for strategies to face legal and technical implications of ICT usage [44]. Again, for some scholars prosumers are considered by firms and companies "operant resources" [45], [6], while others theorize about the relationship between digital prosumption and alienation. For instance, Comor [29] argues that notwithstanding the empowering implications of prosumption and the hope of some analysts for the end of human alienation, the majority of digital prosumers will be alienated anyway. He claims that people will participate in digital prosumption mainly as mere powerless tools of capital or as capital's creative tools, while only a minority of them will employ prosumption in ways capable to redress their alienation [29].

\section{General Overview}

Overall, contrasting perspectives try to give an account of the ontological status of users as digital prosumers and to understand what their fate will be. Depending on positive or negative approaches, the digital prosumer seems destined to prosper as the protagonist of new innovative and socially beneficial practices or to decline from its apparently privileged condition and be incorporated in traditional hierarchical structures and capitalist logics. On one hand, we are witnessing the celebration of users' creativity and choice through prosumption [27], whereas on the other hand online production practices seem to succumb to corporate interests and business purposes. Nevertheless, assuming either a positive or a negative approach for the analysis of productive paradigms in digital environments could limit the comprehension of the above-mentioned practices.

\section{Discussion}

The recent advancements of ICT and the consequent emerging online production practices raised both hopes and concerns regarding the fate of digital prosumers. From the study of users' increased agency and their role and influence in productive paradigms, two main opposing positions seem to have emerged: a positive perspective, often characterized by enthusiastic approaches; and a critical perspective, mainly skeptical about online production practices and their real benefits for users. As already stated, controversies about the beneficial or harmful consequences of digital prosumption continue to multiply. They refer both to phenomena that are under way and to possible future scenarios. They also entail an articulated web of assumptions about people's awareness of pros and cons of ICT usage and their capabilities of coping with them.

The focus of scholars seems to be either on how emerging socio-technical arrangements expand people's possibilities or on how they limit their freedom and contribute to the exploitation of their work and creativity. Several accounts investigate the evolution of the user-technology relation and its effects on positive or negative social change without reaching a substantial agreement. These accounts shape their analyses through the usage of different rhetorical strategies in the attempt to foster narratives able to suggest a progressive empowerment and emancipation of individuals or, on the contrary, an amplification of human misery [4]-[6]. Optimistic and pessimistic positions usually consider specific kinds of social changes or emerging phenomena to stimulate either hope for future possibilities and prosperity or concern for negative potential consequences of prosumers' online practices [4]-[6]. 
As demonstrated, on one hand positive approaches provide examples related to users' empowerment and to the socio-political and economic beneficial effects of prosumers' online production, collaboration and participation. On the other hand, scholars examine how certain emerging socio-technical arrangements facilitate the exploitation of digital prosumers as well as the integration of their activities in already existing hierarchical structures, capitalist logics and systems of control. Nevertheless, specific rhetorical strategies and narratives can negatively affect the understanding of the analyzed phenomena and limit the analysis itself [46]. In reality, opposite perspectives seem somehow to limit the range of online practices taken into account and, in so doing, to affect the analysis of digital prosumer-related phenomena as well as the debate about them.

Indeed, through a further analysis of the different approaches, one sees that the contrasting perspectives taking part in the current debate are not considering the same online practices and kind of users as the objects of their study. Moreover, even when they take into account the same phenomena, instead of placing equal importance on different interrelated aspects (economic, social, political), they tend to privilege the one, or ones, that corroborates their thesis. The fact of taking into account only specific practices or aspects related to online production practices allows scholars to shape a positive or negative social vision of certain phenomena [5], while limiting the object of their analysis. They certainly open up important questions regarding the relation between online productive paradigms and the fate of digital prosumers, yet they underline those cases that support their theses [5].

If we consider the narrative that accompanies positive approaches and the examples that are generally taken into account we find ourselves in front of a specific section of the user base that participates in online production practices. The most common accounts regard online peer-production of cultural and digital goods [8], [9], collaborative open source software development [11], online Hacktivism [15], Do-it-Yourself communities [14], wiki-government [35] and Cyber-democracy [33], [34]. These accounts refer to online practices in which people participate in collaborative activities to satisfy personal needs, to reach common or socially relevant goals, to find solutions to their problems, or to take part in political decisions and initiatives through ICT. In these cases individuals are described as empowered users who exhibit and experience virtuous behavior [9]. Moreover, as the reader can easily understand, the reference here is usually to digital-literate users aware of the pros and cons of ICT usage, or at least capable of participating and collaborating online in an effective way. Besides, the investigated activities result in being, in several ways, always beneficial for the users themselves.

On the contrary, if we investigate negative approaches, it is easy to notice that their analysis does not focus on positive social changes and potentially socially relevant practices but mainly on economic issues and emerging concerns related to privacy and surveillance. In this case, even if we consider the less pessimistic approaches, the main topics are: prosumers' alienation [29], [47], prosumer-management [26], prosumers unawareness of being exploited [3], economic-practical commodification of personal data [41], [42], control and regulation [43], and extraction of unpaid labor [38]-[40]. Evidently, a different and more heterogeneous audience is considered by these approaches. Hence, the spectrum of user base taken into account varies importantly from the one considered by positive approaches. For instance, this spectrum can comprehend low digital-literate users and digital-literate ones unaware of the collateral consequences of their patterns of ICT usage. By collateral consequences of ICT usage is meant the overexposure of data, the tracking of users' online activities, the selling of users' personal data to third parties for advertisement and business interests, and governmental surveillance executed by national security services. Furthermore, the user base considered by pessimistic approaches can also include digital-literate or high-digital literate users engaged in user-corporate relationships who collaborate in product development in exchange for design recognition rather than financial compensation [3], as well as users who take part individually in prosumption activities, more or less consciously trading their privacy and data for free services and goods.

The analysis of different perspectives, narratives and rhetorical strategies help us to be aware of the risks related to the assumption of optimistic and pessimistic positions regarding digital prosumers and online production practices. These risks can be summarized as follows: a limitation of the range of analyzed practices, a narrowing down of the user base taken into account, and a failure to reach a comprehensive understanding of emerging phenomena and to develop an account able to consider simultaneously different, articulated and interrelated aspects (e.g. economic, social, political). Therefore, becoming seduced by utopian or positive positions, or being discouraged by anti-utopian or negative ones could result in being prejudicial and in letting the position we support lead the analysis itself.

Developing an account of emerging online practices in terms of a positive or negative approach could therefore provoke a distortion in the analysis when it comes to the identification of the key processes, practices and actors involved and of the effects and broadly articulated ramifications of the considered phenomena [46]. Even in an unconscious way, the researcher could have the tendency to design the research and tailor the subsequent analysis so as to have a series of data which appear to be a casual chain or logic in which all the elements lead to a conclusion that perfectly matches his/her initial biased assumptions [46]. This could result in an asymmetry between what is presented as a reliable account of emerging phenomena and the synchronic relations of the analyzed practices with positive and negative effects both for individuals and the entire society. Evidently, specific rhetorics, intended as persuasive arguments shaped according to the researcher's intentions and assumptions, can affect importantly the degree of objectivity of the analysis and the overall understanding of the investigated phenomena. Consequently, being aware of their influence on the entire research and its outcomes seems necessary.

As already stated, the accounts of current online practices and emerging socio-technical arrangements vary greatly 
according to the adopted perspective. Their standpoints affect the spectrum of activities and involved actors taken into account and likewise the variety of lenses through which to look at the analyzed phenomena. Therefore, a key issue of the current analysis of online production practices seems to regard how to understand the social opportunities and dilemmas of digital prosumption without becoming fascinated by utopian or positive positions, or being discouraged and influenced by anti-utopian and negative ones [5]. The main question appears to be how to go beyond positive and negative approaches and, in so doing, to reach a more comprehensive understanding of the analyzed phenomena. This issue, that historically characterized the debate on computerization and ICT since their emergence, is still relevant with regard to digital prosumption and seems to affect the understanding of emerging online practices [6].

Certainly, it is hard to believe in the possibility of reaching a broad understanding of digital prosumption and its ramifications while relying on neatly opposite perspectives or strictly defined concepts. This is because the emerging socio-technical arrangements appear to be multifaceted and characterized by a wide and heterogeneous range of involved actors, practices, values, potentialities, criticism and effects. So far, the debate on digital prosumption seems mainly characterized by a dialectic relation between positive and negative approaches that mutually contrast each other. Nevertheless, the themes related to the ontological status of users as digital prosumers and their participation in online production practices are surely complex topics and it would be fruitless to reduce their analysis to preconceived assumptions.

However, there seems to exist a third, less explored position that a researcher can assume in the attempt to fill the gap between the two main perspectives. This possibility consists of analyzing emerging phenomena avoiding the usage of strict definitions or inflexible perspectives and in acknowledging the ambiguity and multivalence of the emerging socio-technical arrangements. To do this, it is necessary to understand productive paradigms in digital environments and the users' role as a coexistence of different heterogeneous practices that do not annihilate each other, but continuously rearticulate the entire scenario [48]. Perhaps the exploitation of this possibility and the adoption of an impartial perspective, intended as the effort to analyze practices in the most neutral possible way, could become the future goal of several researchers interested in digital prosumption.

\section{CONCLUSION}

The recent development of Information and Communication Technologies brought about a progressive change with regard to the users' role in online production practices and related emerging socio-technical arrangements. The ontological status of users as digital prosumers absorbs the attention of scholars in several disciplines and fields of study. Nevertheless, the majority of them seems to embrace either optimistic or pessimistic positions regarding the object of their analysis.
Whether positive or negative positions are assumed depends on which terminology and associations are chosen to represent the new emerging practices and socio-technical arrangements [6]. However, the adoption of specific analytical and rhetorical strategies results in being prejudicial for the analysis itself. Indeed, a further investigation of opposing and contrasting perspectives leads to the detection of the risks related to the employment of neatly positive or negative approaches to the study of emerging productive paradigms in digital environments. These risks are represented by a limitation of the range of analyzed practices, a narrowing down of the user base taken into account and a failure to reach a comprehensive understanding of emerging phenomena as well as to develop an account of current emerging practices able to consider simultaneously different, articulated and interrelated aspects.

Investigating the increased agency of users, their new ontological status as digital prosumers, their role in digital worlds as well as their likely fate seems to require a more neutral and flexible perspective. The awareness that when we talk about emerged and emerging online production practices and the transformations of users' role and agency we refer to the oscillation of continuity and discontinuity and the coexistence of what is and what has been transgressed [48] must always accompany the researcher. Hence, the understanding of current productive paradigms in digital environments and of prosumers' role as a coexistence of different practices that do not annihilate each other but rather rearticulate the entire scenario is necessary [48]. Therefore, the adoption of an impartial perspective, able to conduct to a more neutral and holistic approach and therefore to a potentially broader and deeper comprehension of the investigated phenomena, is suggested to those engaged in the study of digital prosumption.

\section{REFERENCES}

[1] J. V. Dijck, "Users like you? Theorizing agency in user-generated content," Media, Culture, and Society, vol. 31, no. 1, pp. 41-58, 2009.

[2] A. M. Kaplan and M. Haenlein, "Users of the world, unite! The challenges and opportunities of Social Media," Business Horizons, vol. 53, no. 1 , pp. 59-68, 2010.

[3] G. Ritzer, "Prosumption: Evolution, revolution, or eternal return of the same?," Journal of Consumer Culture, vol. 14, no. 1, pp. 3-24, 2014.

[4] R. Kling, "Reading 'all about' computerization: How genre conventions shape nonfiction social analysis," The Information Society, vol. 10, no. 3, pp. 147-172, 1994.

[5] R. Kling, Computerization and Controversy: Value Conflicts and Social Choices, San Francisco: Morgan Kaufmann, 1996.

[6] M. Schäfer, Bastard Culture: How User Participation Transforms Cultural Production, Amsterdam: Amsterdam University Press, vol. 6 , 2011.

[7] M. Schäfer, "Participation inside? User activities between design and appropriation," in Digital Material Tracing New Media in Everyday Life and Technology, M. V. den Boomen, S. Lammes, A. Lehmann, J. Raessens, and M. Schäfer, Ed., Amsterdam: Amsterdam University Press, 2009, pp. 147-158.

[8] D. Tapscott and A. Williams, Wikinomics: How Mass Collaboration Changes Everything, New York: Portfolio, 2006.

[9] Y. Benkler and H. Nissenbaum, "Commons-based peer production and virtue," The Journal of Political Philosophy, vol. 14, no. 4, pp. 394-419, 2006.

[10] T. O'Reilly. (2005). What is Web 2.0: Design Patterns and Business Models for the Next Generation of Software. [Online]. Available: http://www.oreillynet.com/pub/a/oreilly/tim/news/2005/09/30/what-is -web-20.html

[11] A. B. Blogs, Wikipedia, Second Life and Beyond: From Production to Produsage, New York: Peter Lang, 2008. 
[12] B. Hartmann, S. Doorley, and S. R. Klemmer, "Hacking, Mashing, Gluing: A study of opportunistic design and development," Pervasive Computing, vol. 7, no. 3, pp. 46-54, 2006.

[13] C. Ciborra, The Labyrinths of Information: Challenging the Wisdom of Systems, Oxford: Oxford University Press, 2002.

[14] M. Wolf and S. McQuitty, "Understanding the do-it-yourself consumer: DIY motivations and outcomes," AMS Review, vol. 1, pp. 154-170, 2011.

[15] C. Auty, "Political hacktivism: Tool of the underdog or scourge of cyberspace?" ASLIB Proceedings: New Information Perspectives, vol. 56 , no. 4, pp. 212-222, 2004.

[16] L. Raine and B. Wellman, Networked: The New Social Operating System, Cambridge, MA: MIT Press, 2012.

[17] Y. Benkler, The Wealth of Networks: How Social Production Transform Markets and Freedom, London: Yale University Press, 2006.

[18] A. Toffler, The Third Wave, New York: Morrow, 1980.

[19] P. Kotler, "The prosumer movement: A new challenge for marketers," Advances in Consumer Research, vol. 13, no. 1, pp. 510-513, 1986.

[20] G. Ritzer, P. Dean, and N. Jurgenson, "The coming of age of the prosumer," American Behavioral Scientist, vol. 56, no. 4, pp. 379-398, 2012.

[21] G. Ritzer and N. Jurgenson, "Production, Consumption, Prosumption: The nature of capitalism in the age of the digital prosumer," Journal of Consumer Culture, vol. 10, no. 1, pp. 13-36, 2010.

[22] G. Ritzer, The McDonaldization of Society, 6th ed. Thousand Oaks, CA: Pine Forge Press, 2011.

[23] E. V. Hippel, Democratizing Innovation, Cambridge: MIT Press, 2005.

[24] C. K. Prahalad and V. Ramaswamy, "Co-creation experiences: The next practice in value creation," Journal of Interactive Marketing, vol. 18 , no. 3, pp. 5-14, 2004.

[25] S. Knott, "Design in the age of prosumption: The craft of design after the object," Design and Culture, vol. 5, no. 1, pp. 45-67, 2013.

[26] M. Johnson, H. Mozaffar, G. M. Campagnolo, S. Hyysalo, N. Pollock, and R. Williams, "The managed prosumer: Evolving knowledge strategies in the design of information infrastructures," Information, Communication and Society, vol. 17, no. 7, pp. 795-813, 2014.

[27] D. Zwick, S. K. Bonsu, and A. Darmody, "Putting consumers to work co-creation and new marketing govern-mentality," Journal of Consumer Culture, vol. 8, no. 2, pp. 163-196, 2008.

[28] C. Leadbeater and P. Miller, The Pro-Am Revolution: How Enthusiasts are Changing our Economy and Society, London: Demos, 2004.

[29] E. Comor, "Digital prosumption and alienation," Ephemera, vol. 10, pp 439-454, 2010.

[30] J. Söderberg. (2002). Copyleft vs copyright: A Marxist critique First $\begin{array}{lll}\text { Monday. } & \text { [Online]. } & \end{array}$ http://dx.doi.org/10.5210/fm.v7i3.938

[31] W. Uricchio, "Cultural citizenship in the age of P2P networks," in European Culture and the Media, I. Bondebjerg and P. Golding, Ed., Bristol: Intellect Books, 2004, pp. 139-164.

[32] L. Lessig, Remix, New York: Penguin Press, 2008.
[33] P. Lévy, Cyberdémocratie, Essai De Philosophie Politique, Paris: Odile Jacob, 2002.

[34] P. Lévy, "Collective intelligence, a civilisation: Towards a method of positive interpretation," International Journal of Politics, Culture, and Society, vol. 18, pp. 189-198, 2005.

[35] B. S. Noveck, Wiki Government. How Technology can Make Government Better, Democracy Stronger, and Citizens more Powerful, Washington D.C.: Brookings Institution Press, 2009.

[36] S. Lash, Critique of Information, London: Sage, 2002.

[37] S. D. Paoli and C. Storni, "Produsage in hybrid networks: sociotechnical skills in the case of Arduino," New Review of Hypermedia and Multimedia, vol. 17, no. 1, pp. 31-52, 2011.

[38] T. Terranova, "Free labor: Producing culture for the digital economy," Social Text, vol. 18, no. 2, pp. 33-58, 2000.

[39] T. Terranova, Network Culture: Politics for the Information Age, London: Pluto Press, 2004.

[40] M. Andrejevic, "Surveillance and alienation in the online economy," Surveillance and Society, vol. 8, no. 3, pp. 278-287, 2011.

[41] M. Zimmer. (2008). The Externalities of Search 2.0: The Emerging Privacy Threats When the Drive for the Perfect Search Engine Meets Web 2.0. First Monday. [Online]. 13(3). Available: http://dx.doi.org/10.5210/fm.v13i3.2136

[42] C. Fuchs. (2009). Social networking sites and the surveillance society. ICT\&S Center Research Report, Salzburg, Vienna. [Online]. Available: http://fuchs.icts.sbg.ac.at/SNS_Surveillance_Fuchs>.pdf

[43] W. Chun, Control and Freedom Power and Paranoia in the Age of Fiber Optics, Cambridge, MA: MIT Press, 2006.

[44] S. Sevignani, "The commodification of privacy on the internet," Science and Public Policy, vol. 40, no. 6, pp. 733-739, 2013.

[45] S. L. Vargo and R. F. Lusch, "Evolving to a new dominant logic for marketing," Journal of Marketing, vol. 68, no. 1, pp. 1-17, 2004.

[46] A. Sayer, Method in Social Science: A Realist Approach, 2nd ed. London: Routledge, 2010.

[47] E. Comor, "Contextualizing and critiquing the fantastic prosumer: Power, alienation and hegemony," Critical Sociology, vol. 37, no. 3, pp. 309-327, 2010.

[48] N. Carpentier, K. Schröder, and L. Hallett, Audience Transformations: Shifting Audience Positions in Late Modernity, London: Routledge, 2013.

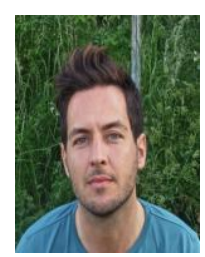

Davide Dusi is a $\mathrm{PhD}$ student at the Centre for Social Theory of Ghent University. He obtained his BA in education sciences at University of Verona in 2008, and his MA in sociology at University of Trento in 2012. Currently, his research concerns productive paradigms in digital environments and related phenomena such as prosumer movement and user participation through social media. He is also interested in participatory design of ICT and in societal innovation driven by digital innovation. 